\title{
Mobilisable strength design for flexible embedded retaining walls
}

\author{
M. DIAKOUMI and W. POWRIE
}

\begin{abstract}
Soil-structure interaction may have an important influence on the behaviour of embedded retaining walls, affecting both wall bending moments and ground movements. However, it can be difficult and time consuming to capture in design, especially in a way that gives a physical insight into the key behavioural mechanisms involved. A calculation procedure has been developed for retaining walls propped near the crest that takes into account both the non-linearity of the stress-strain behaviour of the soil and the flexibility of the wall. Results for different pore water pressure conditions, soil strengths and soil and wall stiffnesses are presented in the form of look-up charts, and are compared with those derived from factored limit equilibrium analyses. A dimensionless parameter is introduced to represent the relative soil-wall stiffness, and its importance is demonstrated. A critical flexibility ratio is identified at which the bending moments start to reduce below those given by a conventional limit equilibrium calculation. This ratio is linked to the wall deflection, and is used to distinguish a stiff from a flexible system in soils of different strengths and pore water pressure conditions. The approach is discussed in relation to previous studies.
\end{abstract}

KEYWORDS: design; limit state design/analysis; retaining walls; shear strength; soil/structure interaction; stiffness

\section{INTRODUCTION}

Limit equilibrium calculations with the soil strength reduced by a factor of safety, $F_{\mathrm{s}}$, are commonly used in practice to ensure that the wall is remote from the ultimate limit state (ULS). Guidelines to avoid the serviceability limit state (SLS) are fewer and less clear than for the ULS, since deformations are often assumed to be a secondary problem. Where deformations are calculated, it is normally done using relatively simple programs based on elasticity; in reality, soil stiffness depends on stress history, stress state, stress path and strain, and may well be anisotropic. More rigorous soilstructure interaction analysis may be carried out numerically using finite-element or finite-difference analysis. However, the number of parameters involved, the potential sensitivity of the results to the values adopted, the cost and the user expertise required tend to restrict the use of these methods to major projects. Past experience and recorded behaviour of retaining walls can provide guidance, but are only really applicable in directly comparable cases.

Rowe (1952) showed that the flexibility of an embedded retaining wall anchored near the crest will reduce the bending moments in comparison with those calculated in a conventional limit equilibrium analysis. Rowe (1955) introduced a dimensionless group, $m \rho$, to characterise the relative soil-wall stiffness (where $m$ is a measure of the soil stiffness, $\rho=H^{4} / E I, H$ is the total wall length, and $E I$ is the wall bending stiffness), and presented look-up charts from which the degree of bending moment or prop load reduction due to the relative soil-wall flexibility could be estimated. However, Rowe's analysis is now not often used in routine design, primarily because it

(a) was aimed at sheet-pile walls in dry sands, which defined

Manuscript received 5 May 2011; revised manuscript accepted 17 May 2012. Published online ahead of print 14 September 2012.

Discussion on this paper closes on 1 July 2013, for further details see p. ii.

$*$ Built Environment \& Civil Engineering Division, School of Environment \& Technology, University of Brighton, UK.

$\uparrow$ School of Civil Engineering \& the Environment, University of Southampton, UK the range of retained height to embedment ratios considered

(b) was based on a limit equilibrium calculation in which the factor of safety was applied entirely to the passive lateral stresses in front of the wall with fully active stresses behind, in contrast to the modern approach in which the factor of safety is applied equally to the soil behind and in front of the wall

(c) used a non-fundamental soil stiffness parameter that is difficult to measure.

Potts \& Fourie (1985) presented the results of finite-element analyses carried out to investigate the effect of the wall bending stiffness, $E I$, on bending moments and prop loads in a wall propped at the crest for different values of pre-excavation earth pressure coefficient. The soil Young's modulus increased linearly with depth but did not vary with strain, and pore water pressures were assumed to be zero. For flexible walls, the maximum bending moments and prop loads were less than those determined from a limit equilibrium calculation with the factor of safety $F_{\mathrm{r}}$ applied as proposed by Burland et al. (1981), and reduced with increasing wall flexibility. Conversely, for stiff walls and an initial earth pressure coefficient greater than 1, the maximum bending moments and prop loads exceeded the limit equilibrium values.

\section{Mobilisable strength design}

Mobilisable strength design is a method of calculation linking the strength mobilised in the soil around a geotechnical structure to the deformation using an idealised displacement field and the condition of equilibrium, enabling the movements under working conditions to be estimated. It was described for rigid embedded retaining walls by Bolton et al. (1989, 1990), who idealised the soil behaviour by means of simplified kinematically admissible strain fields proposed by Bolton \& Powrie (1988) and Bransby \& Milligan (1975); and was termed mobilisable strength design (MSD) byOsman \& Bolton (2004).

Diakoumi (2007) and Diakoumi \& Powrie (2009) applied the MSD method to flexible walls propped at the crest, by 
introducing new kinematically admissible strain fields to represent the effect of wall bending both on the lateral stress distribution in the soil and on wall movements. The strain fields for a flexible wall were introduced by subdividing the soil surrounding the wall into a number of pairs of triangles, representing the superposition of a number of the strain fields proposed by Bolton \& Powrie (1988) for a rigid wall propped at the crest, relating to a series of depths down the wall, as shown in Fig. 1.

For the analyses presented by Diakoumi \& Powrie (2009) and in this paper, the soil is divided into four zones behind the wall and two zones in front. In principle, the soil could be divided into more zones to achieve a smoother approximation to the deflected shape and/or take account of different soil layers. The triangles are free to slide on vertical and horizontal surfaces, which are assumed to be frictionless. Within each pair, the triangle adjacent to the wall (OAJ, $\mathrm{OBH}$, etc.) remains rigid while the complementary triangle making up the square of the mechanism (ARJ, BQH, etc.) undergoes a shear strain related to the rotation of the wall section under consideration. Outside the square of the mechanism (OARJ, OBQH, etc.), the soil is assumed not to deform, as changes in stress will be small.

The distributed wall bending stiffness $E I$ is idealised into rotational springs at discrete points down the depth of the wall, separated by rigid wall elements. The rotation of each section of the wall is related to the shear strain and, by means of a modified hyperbolic stress-strain law, to the mobilised soil strength, in the lower triangle of the adjacent soil zone. The use of the additional kinematically admissible strain fields permits the introduction of different mobilised shear strengths, corresponding to different shear strains in each soil zone, consistent with the variation in local rotation of a flexible wall. The equations of global equilibrium for the wall, and local equilibrium at each rotational spring, are then used to determine the wall prop loads and bending moments under working conditions. Diakoumi \& Powrie (2009) presented results of the method for a single value of soil strength at failure, $\varphi_{\text {ult }}^{\prime}$, and hydrostatic pore pressures below a water table at ground level.

This paper develops the MSD method presented by Diakoumi \& Powrie (2009) further, to

(a) enable the estimation of the bending moments and prop loads associated with a flexible retaining wall propped at the crest for a variety of groundwater conditions and a range of values of wall stiffness and $\varphi_{\text {ult }}^{\prime}$ in a practical and reasonably accurate manner (b) introduce an appropriate dimensionless relative soil-wall stiffness number based on conventional and measurable parameters

(c) relate both of these to the factored ULS limit equilibrium calculation specified in modern codes of practice, in a way suitable for use in design

(d) compare the results with previously published studies.

The calculation steps involved in the development of the MSD method for flexible retaining walls propped at the crest presented by Diakoumi \& Powrie (2009) may be summarised as follows.

The design value of the ratio of the retained to overall wall height, $n_{\text {des }}$, is determined by a factored limit equilibrium calculation in the usual way, on the basis of the same, uniform mobilised soil strength (effective angle of shearing) $\varphi_{\mathrm{des}}^{\prime}$ on both sides of the wall.

For this value of $n_{\text {des }}$, the wall rotation is assumed to take place in four successive stages, as shown in Fig. 1. The first stage consists of the rotation of the entire wall (OF) by an amount $\delta \theta_{4}$, and with it the triangles ODF (behind the wall) and HFL (in front). According to the geostructural mechanism presented by Bolton \& Powrie (1988), the wall rotation, $\delta \theta_{4}$, is related to the incremental shear strain in the associated complementary soil triangle DEF by

$$
\delta \gamma_{4}=2 \delta \theta_{4}
$$

Triangle LFK in front of the wall will be compressed, and the maximum shear strain increment within it, $\delta \gamma_{5}$, is related to the wall rotation by

$$
\delta \gamma_{5}=\frac{2 \delta \theta_{4}(h+d)}{d}
$$

where $h$ is the retained height, and $d$ is the embedded depth. Compression is taken as positive.

The second stage of wall movement consists of the further rotation of the wall section OG together with the triangles OCG behind and HGM in front, by an amount $\delta \theta_{3}$. The corresponding maximum shear strain increments $\delta \gamma_{3}$ and $\delta \gamma_{6}$ within the associated complementary triangles CPG and MGN are given by

$$
\begin{aligned}
& \delta \gamma_{3}=2 \delta \theta_{3} \\
& \delta \gamma_{6}=\frac{2 \delta \theta_{3}(h+d / 2)}{d / 2}
\end{aligned}
$$

Similarly, the third and fourth stages of wall movement

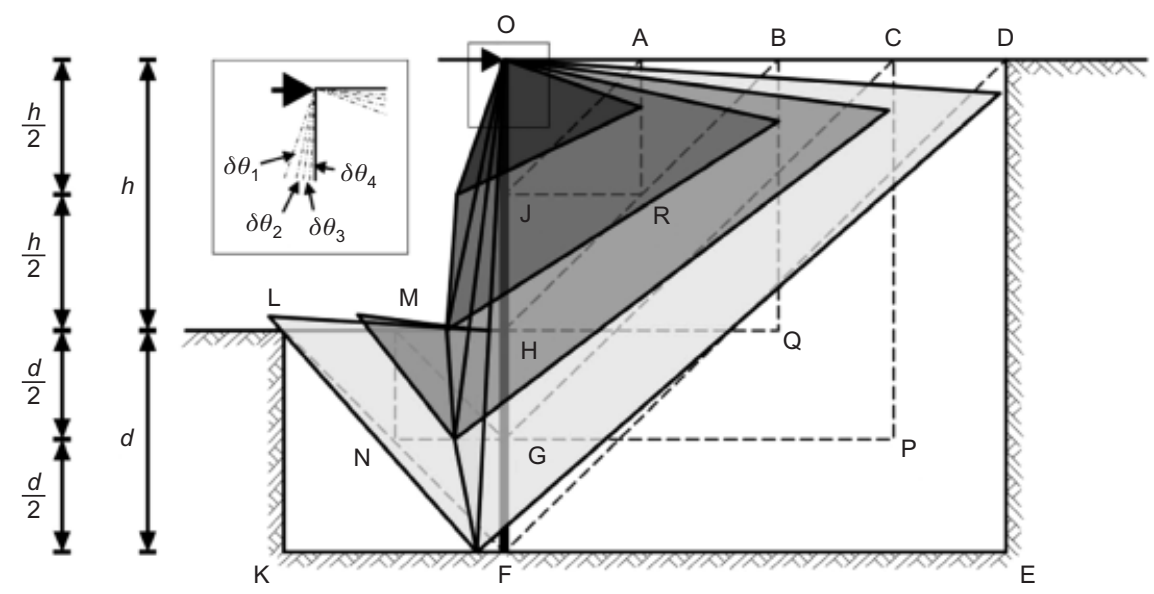

Fig. 1. Admissible strain fields for flexible retaining wall propped at crest rotating in four successive stages 
consist of the rotation $\delta \theta_{2}$ of the wall section $\mathrm{OH}$ and triangle $\mathrm{OBH}$ behind the wall, and $\delta \theta_{1}$ of the wall section $\mathrm{OJ}$ and triangle OAJ, resulting in maximum shear strain increments $\delta \gamma_{2}$ within $\mathrm{BQH}$ and $\delta \gamma_{1}$ within ARJ of

$$
\begin{aligned}
& \delta \gamma_{2}=2 \delta \theta_{2} \\
& \delta \gamma_{1}=2 \delta \theta_{1}
\end{aligned}
$$

The total shear strain within each triangle is then taken as the sum of the incremental shear strains imposed on the triangle during each stage of wall rotation. Thus for triangles $\mathrm{DEF}, \mathrm{CPG}, \mathrm{BQH}$ and $\mathrm{ARJ}$ behind the wall the total shear strains $\gamma_{4}, \gamma_{3}, \gamma_{2}$ and $\gamma_{1}$ are given by

$$
\begin{aligned}
& \gamma_{4}=\delta \gamma_{4}=2 \delta \theta_{4} \\
& \gamma_{3}=\delta \gamma_{4}+\delta \gamma_{3}=2\left(\delta \theta_{4}+\delta \theta_{3}\right) \\
& \gamma_{2}=\delta \gamma_{4}+\delta \gamma_{3}+\delta \gamma_{2}=2\left(\delta \theta_{4}+\delta \theta_{3}+\delta \theta_{2}\right) \\
& \gamma_{1}=\delta \gamma_{4}+\delta \gamma_{3}+\delta \gamma_{2}+\delta \gamma_{1}=2\left(\delta \theta_{4}+\delta \theta_{3}+\delta \theta_{2}+\delta \theta_{1}\right)
\end{aligned}
$$

For triangles LFK and MGN in front of the wall, the total shear strains $\gamma_{5}$ and $\gamma_{6}$ are given by

$$
\begin{aligned}
& \gamma_{5}=\delta \gamma_{5}=\frac{2 \delta \theta_{4}(h+d)}{d} \\
& \gamma_{6}=\delta \gamma_{5}+\delta \gamma_{6}=\frac{2 \delta \theta_{4}(h+d)}{d}+\frac{2 \delta \theta_{3}(h+d / 2)}{d / 2}
\end{aligned}
$$

This is not a superposition of shear strains within a given physical zone of soil, but the summation of the shear strains associated with the rotation of a given section of the wall, which could occur in different and non-overlapping zones of soil.

The summated shear strain $\gamma_{i}$ is then related to the mobilised soil strength $\varphi_{\text {mobi }}^{\prime}$ associated with the $i$ th section of the wall by means of a modified hyperbolic stress-strain law

$$
\varphi_{\mathrm{mob} i}^{\prime}=\sin ^{-1}\left(\frac{\gamma_{i}}{A+B \gamma_{i}}\right)
$$

Parameters $A$ and $B$ in equation (13) can be related to the rate of increase of shear modulus $G$ with depth, $G^{*}$, and the soil strength at failure, $\varphi_{\text {ult }}^{\prime}$, and can be determined from laboratory element tests. The derivation of the modified hyperbolic stress-strain equation and the parameters $A$ and $B$ for different groundwater conditions is presented in the following section.

The active and passive pressures $\sigma_{\mathrm{h} i}^{\prime}$ behind and in front of the retaining wall are assumed to vary linearly with depth within each section, with active and passive earth pressure coefficients $K_{\mathrm{a} i}$ and $K_{\mathrm{p} i}$ (which are different for each wall section as the mobilised strengths $\varphi_{\text {mobi }}^{\prime}$ are different) calculated according to the equations given in Eurocode 7 (EC7; British Standards Institution, 2004) and Powrie (1997). From the equations of global equilibrium for the wall and the idealised lateral stress distribution, the normalised bending moments $M_{i} /\left(\gamma_{\mathrm{s}} H^{3}\right)$, where $\gamma_{\mathrm{s}}$ is the soil unit weight, are determined. These will depend on $\delta \theta_{i}, \varphi_{\text {ult }}^{\prime}$ and $G^{*}$.

A key feature of the approach is that the continuous flexural rigidity of the wall, EI, is idealised into rotational springs at discrete points down the depth of the wall, separated by rigid wall elements. The discrete points correspond to the vertices of the rigid triangles (OAJ, OBH, etc.) on either side, as shown in Fig. 1. The spring stiffness is EI divided by the average length of the two rigid sections on either side. For example, the spring rotational stiffness $k_{1}$, at point $\mathrm{J}$ on the wall, is given by

$$
k_{1}=\frac{E I}{h / 4+h / 4}=\frac{2 E I}{h}
$$

Diakoumi (2007) shows that this introduces an error of less than $6 \%$ in the deflected shape for simply supported beams and cantilevers subject to uniform and triangular loads.

The rotational spring stiffness $k_{i}$, given (for example) by equation (14), is also equal to $M_{i} / \theta_{i}$, where $M_{i}$ is the bending moment and $\theta_{i}$ is the relative rotation between the wall sections at the $i$ th discrete point. Geometry is used to relate the node rotations, $\theta_{i}$, to the rotations of the rigid wall sections $\delta \theta_{i}$. For example, from the above and equation (14), the normalised bending moment $M_{1} /\left(\gamma_{\mathrm{s}} H^{3}\right)$ at point $\mathrm{J}$ as shown in Fig. 1 is

$$
\begin{aligned}
\frac{M_{1}}{\gamma_{\mathrm{s}} H^{3}} & =\frac{k_{1} \theta_{1}}{\gamma_{\mathrm{s}} H^{3}} \\
& =\frac{(2 E I)\left(2 \delta \theta_{1}\right)}{h \gamma_{\mathrm{s}} H^{3}} \\
& =\frac{4 \delta \theta_{1}}{n_{\mathrm{des}} \gamma_{\mathrm{s}} \rho}
\end{aligned}
$$

where $\rho=H^{4} / E I$ is the wall flexibility as defined by Rowe (1952), $H$ is the overall wall height, and $E I$ is its bending stiffness per meter run.

Substitution of the expressions for the normalised bending moments derived from the condition of local equilibrium at each rotational spring (e.g. equation (15)) into the equations derived from the global and horizontal equilibrium for the wall gives a system of five equations in five unknowns: the incremental wall section rotations $\delta \theta_{1}, \delta \theta_{2}, \delta \theta_{3}, \delta \theta_{4}$ associated with the triangles in the active and passive soil zones (Fig. 1), and the prop load, F. Solution of this system requires knowledge of the soil parameters $A, B$ and the dimensionless quantity $\gamma_{\mathrm{s}} \rho$.

\section{MODELLING SOIL BEHAVIOUR}

Hyperbolic stress-strain relationship

Diakoumi \& Powrie (2009) showed that the hyperbolic equation introduced by Kondner (1963), Kondner \& Zelasko (1963) and Duncan \& Chang (1970) for representing the non-linear and stress-dependent behaviour of soils may be rewritten to relate the shear stress $t$ to shear strain $\gamma$. Assuming zero volumetric strain

$$
t=\frac{\gamma}{3 a+2 b \gamma}
$$

(see Appendix 1). The parameters $a$ and $b$ are related to the initial shear modulus $G_{0}$, Poisson's ratio $v$ and shear stress at failure, $t_{\mathrm{f}}$, by

$$
\begin{aligned}
& a=\frac{1}{2 G_{0}(1+v)} \\
& b=\frac{1}{2 t_{\mathrm{f}}}
\end{aligned}
$$

The Duncan \& Chang (1970) formulation was in terms of total stresses for data from undrained triaxial tests. Diakoumi (2007) shows that it is broadly consistent with effective stress-strain relationships proposed by Jardine et al. (1986), Allman \& Atkinson (1992) and Smith et al. (1992), some of which are apparently rather more complex. In this paper, the hyperbolic stress-strain function is interpreted in terms of effective stresses, although the assumption of zero volume change $\left(v^{\prime}=0 \cdot 5\right)$ is retained; this implies drained conditions and soil straining at constant volume, and is consistent with 
the critical state concept. This assumption is not unrealistic for most soils, and is more conservative than upper-bound analyses that assume an angle of dilation equal to the soil strength at failure $\left(\varphi_{\mathrm{ult}}^{\prime}\right)$, which can be maintained only if and while the soil continues to dilate.

\section{Mobilised strength}

The rate of change of mobilised strength, $\varphi_{\mathrm{mob}}^{\prime}$, with shear strain is a useful way of expressing both the development of strength and the stiffness of a soil (Bolton \& Powrie, 1988). It is shown in Appendix 2 that equation (16) may be rewritten in these terms as

$$
\varphi_{\mathrm{mob}}^{\prime}=\sin ^{-1}\left(\frac{\gamma}{A+B \gamma}\right)
$$

Parameters $A$ and $B$ depend on the pore water pressure conditions, as described below and later.

\section{CONDITIONS OF ZERO PORE WATER PRESSURE}

For conditions of zero pore water pressure, it is shown in Appendix 2 that the parameters $A$ and $B$ can be calculated as

$$
\begin{aligned}
& A=\gamma_{\mathrm{s}} / G^{*} \\
& B=\frac{1}{\sin \varphi_{\mathrm{ult}}^{\prime}}
\end{aligned}
$$

The shear strain can be related to the mobilised strength by equation (19), with the parameters $A$ and $B$ determined from appropriate laboratory element tests.

To explore the rotations, normalised bending moments and prop load associated with a retaining wall propped at the crest for a range of wall flexibilities embedded in a variety of soil types, the system of equations derived from the MSD calculations described above was solved numerically using Wolfram Mathematica (version 6.0). Values of $\varphi_{\text {ult }}^{\prime}$ between $20^{\circ}$ and $40^{\circ}, \log \left(\gamma_{\mathrm{s}} \rho\right)$ between $-2 \cdot 86$ and $2 \cdot 14$, and $G^{*}$ between $10^{5}$ and $10^{2} \mathrm{kN} / \mathrm{m}^{3}$ were considered, assuming zero pore water pressures. A value of wall friction $\delta_{\mathrm{s}}=2 \varphi_{\mathrm{mob}}^{\prime} / 3$ was used in the MSD calculations, as recommended by EC7 for sheet-pile walls.

Parameter $A$ was calculated for $v^{\prime}=0.5$ and $\gamma_{\mathrm{s}}=20 \mathrm{kN} / \mathrm{m}^{3}$. The wall flexibility values $\left(\log \left[\gamma_{\mathrm{s}} \rho\right]\right)$ correspond to rigid, diaphragm, sheet-pile and soft retaining walls of total height $20 \mathrm{~m}$ with $\gamma_{\mathrm{s}}=20 \mathrm{kN} / \mathrm{m}^{3}$, as indicated in Table 1 . The values used for the diaphragm and sheet-pile walls are typical of an uncracked reinforced concrete section of $1 \mathrm{~m}$ thickness and a Larssen 4B section respectively, and are consistent with those used by Potts \& Fourie (1985) and Diakoumi \& Powrie (2009) (Table 1). The rigid and soft walls represent extreme cases, beyond likely practical limits which are probably represented by the diaphragm and sheet-pile walls. Similarly, the maximum value of $G^{*}$ may be unrealistically high, but is included to represent an extreme case.

The maximum bending moments, $M$, and prop loads, $F$, obtained from the MSD SLS calculation are normalised by the values $M_{\mathrm{EC} 7}$ and $F_{\mathrm{EC} 7}$ calculated on the basis of a uniform mobilised strength, $\varphi_{\text {des }}^{\prime}$, according to the factored ULS calculation given in EC7. The ratios of $M / M_{\mathrm{EC} 7}$ and $F / F_{\mathrm{EC} 7}$ are plotted in Figs 2 and 3 for different values of wall flexibility and soil stiffness, for an angle of shearing resistance representative of clays $\left(\varphi_{\mathrm{ult}}^{\prime}=20^{\circ}\right)$.

In Figs 2 and 3 the origin of axes is at $(0,1)$. The $x$ axis represents equality between the maximum bending moments and prop loads calculated according to the MSD method and EC7. The implication is that where the curve lies above the $x$ axis the EC7 approach might underpredict, and where the curve is below the $x$ axis might overpredict, the maximum bending moment and prop load, compared with the MSD method. In particular, as the wall flexibility $\rho$ or the soil stiffness $G^{*}$ increases, the maximum bending moment and prop load reduce below their limit equilibrium values. This pattern of reduction is similar for different values of $\varphi_{\text {ult }}^{\prime}$ (Diakoumi, 2007, and Figs 7 and 8).

For a given value of $\varphi_{\text {ult }}^{\prime}$ and soil stiffness, a low wall flexibility apparently gives bending moments and prop loads greater than those calculated using the EC7 uniform mobilised strength approach. This is because for a rigid wall, according to the geostructural mechanism shown in Fig. 1, the shear strain in the soil in front of the wall is greater (by a factor $1+h / d$ or $1 /(1-n))$ than the shear strain in the soil

Table 1. Wall flexibilities for different types of retaining wall

\begin{tabular}{l|c|c|c|c}
\hline & Rigid & Diaphragm & Sheet pile & Soft \\
\hline$E I: \mathrm{kN} \mathrm{m}^{2} / \mathrm{m}$ & $2.33 \times 10^{9}$ & $2.33 \times 10^{6}$ & $7.8 \times 10^{4}$ & $2.33 \times 10^{4}$ \\
$\rho: \mathrm{m}^{3} / \mathrm{kN}$ & $6.87 \times 10^{-5}$ & $6.87 \times 10^{-2}$ & 2.05 & 6.87 \\
$\log \left(\gamma_{\mathrm{s}} \rho\right)$ & -2.86 & 0.14 & 1.61 & 2.14 \\
\hline
\end{tabular}
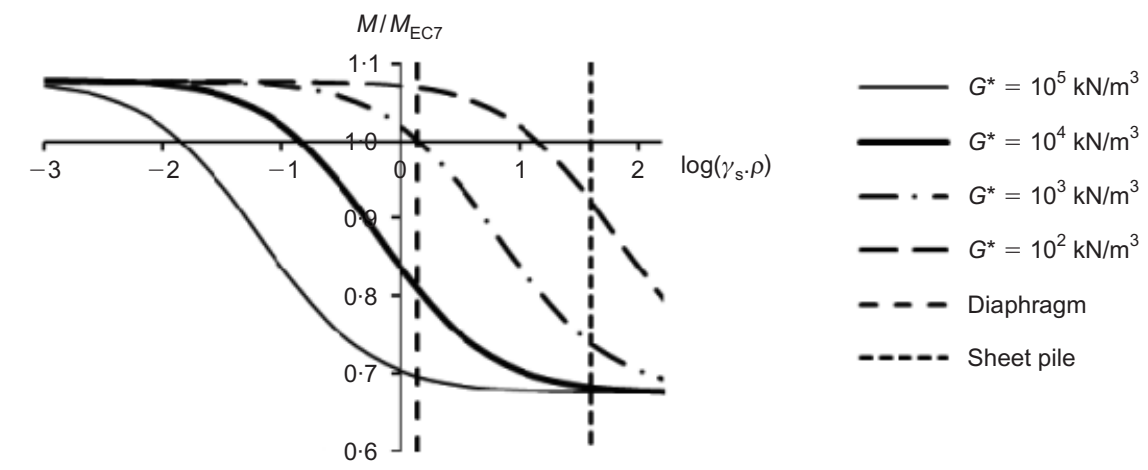

Fig. 2. Comparison between MSD and conventional limit equilibrium (EC7) maximum bending moments for different values of soil stiffness and wall flexibility for $\varphi_{\text {ult }}^{\prime}=20^{\circ}$ and conditions of zero pore water pressure (soil-wall friction angle $\delta_{\mathrm{s}}=\frac{2}{3} \varphi_{\mathrm{ult}}^{\prime}$ ) 


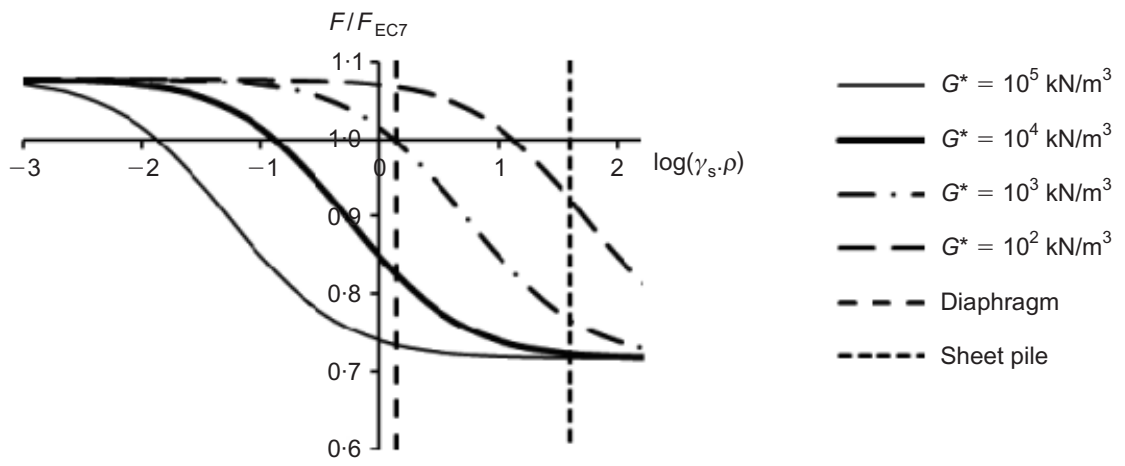

Fig. 3. Comparison between MSD and conventional limit equilibrium (EC7) prop loads at crest for different values of soil stiffness and wall flexibility for $\varphi_{\text {ult }}^{\prime}=20^{\circ}$ and conditions of zero pore water pressure (soil-wall friction angle $\delta_{\mathrm{s}}=\frac{2}{3} \varphi_{\mathrm{ult}}^{\prime}$ )

behind. Assuming the same rate of mobilisation of soil strength with shear strain behind and in front of the wall (as in the calculations presented here) will result in the mobilisation of a strength greater than $\varphi_{\text {des }}^{\prime}$ in the soil in front of the wall, and a strength less than $\varphi_{\text {des }}^{\prime}$ in the soil behind. This leads to higher lateral stresses behind the wall, and hence increased bending moments and prop loads. However, it is unlikely to occur in practice, as the rate of mobilisation of soil strength with shear strain or wall rotation is likely to be greater behind the wall than in front (Powrie et al., 1998). Also, the very high wall and soil stiffnesses included in Figs 2 and 3 are, as already mentioned, unlikely to be encountered in practice.

For the likely range of real wall flexibilities, a reduction in both the maximum bending moment and the prop load is shown in Figs 2 and 3, except for stiffer walls with $G^{*}<10^{2} \mathrm{kN} / \mathrm{m}^{3}$.

\section{LINEAR SEEPAGE FROM AN ORIGINAL}

\section{GROUNDWATER TABLE AT GROUND LEVEL}

Figure 4 shows the idealised 'linear seepage' pore water pressure distribution often adopted to represent steady-state groundwater flow between the groundwater level on the active side to excavation level on the passive side (Symons, 1983); the excess (total) head difference between the soil surfaces behind and in front of the wall is assumed to dissipate uniformly along the flow path. In Fig. $4 h, d, u$ and $F$ denote the retained wall height, wall embedment depth, pore water pressure and prop load respectively.

For a head drop around the wall of $h$ and a flow path length $l=2 d+h$, the pore water pressure at the toe, $u_{\text {toe }}$, is given by

$$
u_{\mathrm{toe}}=\frac{2 \gamma_{\mathrm{w}} d(h+d)}{2 d+h}
$$

where $\gamma_{\mathrm{w}}$ is the unit weight of water.

The seepage pore pressure gradient behind the wall, $(\mathrm{d} u /$ $\mathrm{d} z)_{\mathrm{a}}$, is

$$
\left(\frac{\mathrm{d} u}{\mathrm{~d} z}\right)_{\mathrm{a}}=\frac{2 \gamma_{\mathrm{w}}(1-n)}{2-n}
$$

and that in front of the wall, $(\mathrm{d} u / \mathrm{d} z)_{\mathrm{p}}$, is

$$
\left(\frac{\mathrm{d} u}{\mathrm{~d} z}\right)_{\mathrm{p}}=\frac{2 \gamma_{\mathrm{w}}}{2-n}
$$

where $n=h / H$.

It is shown in Appendix 2 that

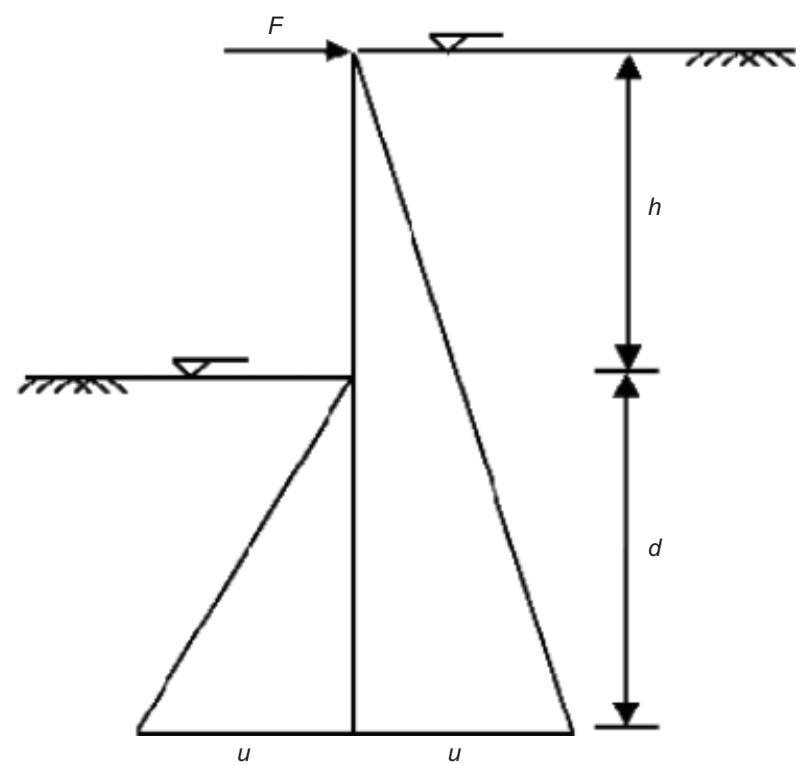

Fig. 4. Pore water pressure distribution for embedded retaining wall with steady-state seepage between groundwater tables at ground level behind and in front

$$
\begin{aligned}
& A=\frac{\gamma_{\mathrm{s}}-(\mathrm{d} u / \mathrm{d} z)}{G^{*}} \\
& B=\frac{1}{\sin \varphi_{\mathrm{ult}}^{\prime}}
\end{aligned}
$$

with $\mathrm{d} u / \mathrm{d} z$ behind and in front of the wall given by equations (23) and (24) respectively.

The system of equations derived from the MSD calculation was solved numerically for the same ranges of values of $\varphi_{\text {ult }}^{\prime}, \log \left(\gamma_{\mathrm{s}} \rho\right)$ and $G^{*}$ used in the analysis for zero pore water pressures, and with $\delta_{\mathrm{s}}=2 \varphi_{\mathrm{mob}}^{\prime} / 3$. Parameter $A$ was calculated for $v^{\prime}=0 \cdot 5, \gamma_{\mathrm{w}}=10 \mathrm{kN} / \mathrm{m}^{3}$ and $\gamma_{\mathrm{s}}=20 \mathrm{kN} / \mathrm{m}^{3}$. The ratios $M / M_{\mathrm{EC} 7}$ and $F / F_{\mathrm{EC} 7}$ are plotted in Figs 5 and 6 for $\varphi_{\mathrm{ult}}^{\prime}=20^{\circ}$.

For very stiff walls, the MSD maximum bending moments and prop loads slightly exceed those calculated using the conventional EC7 limit equilibrium approach; conversely, as the wall flexibility or the soil stiffness increases, they reduce below the limit equilibrium values. The pattern of reduction is similar to that for zero pore water pressure conditions (Figs 2 and 3), although the rate of reduction with increasing wall flexibility or soil stiffness is slightly less pronounced. Again, for the range of wall flexibility values commonly adopted in practice, a reduction in both the maximum bending moment and prop load is apparent. 


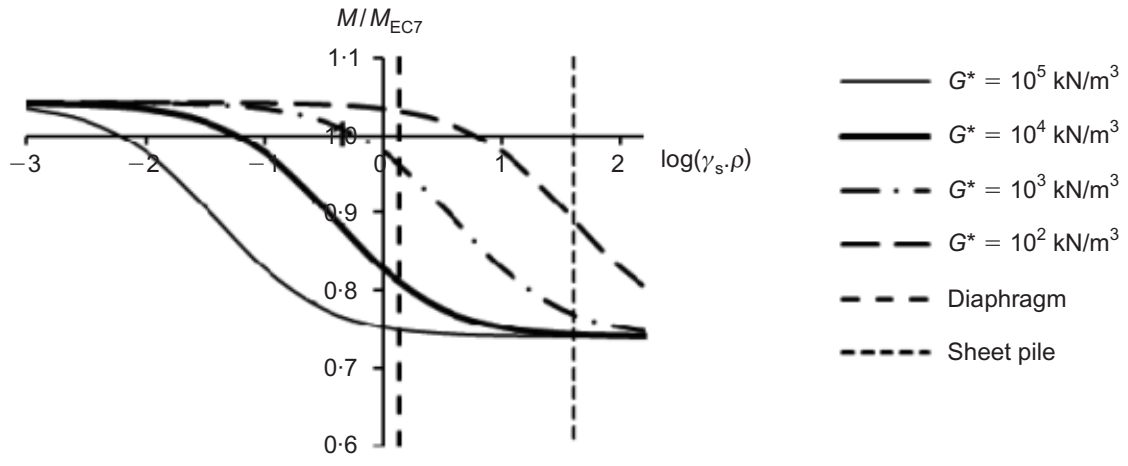

Fig. 5. Comparison between MSD and conventional limit equilibrium (EC7) maximum bending moments for different values of soil stiffness and wall flexibility for $\varphi_{\text {ult }}^{\prime}=20^{\circ}$ and steady-state seepage into excavation from water table at original ground level (soilwall friction angle $\delta_{\mathrm{s}}=\frac{2}{3} \varphi_{\mathrm{ult}}^{\prime}$ )

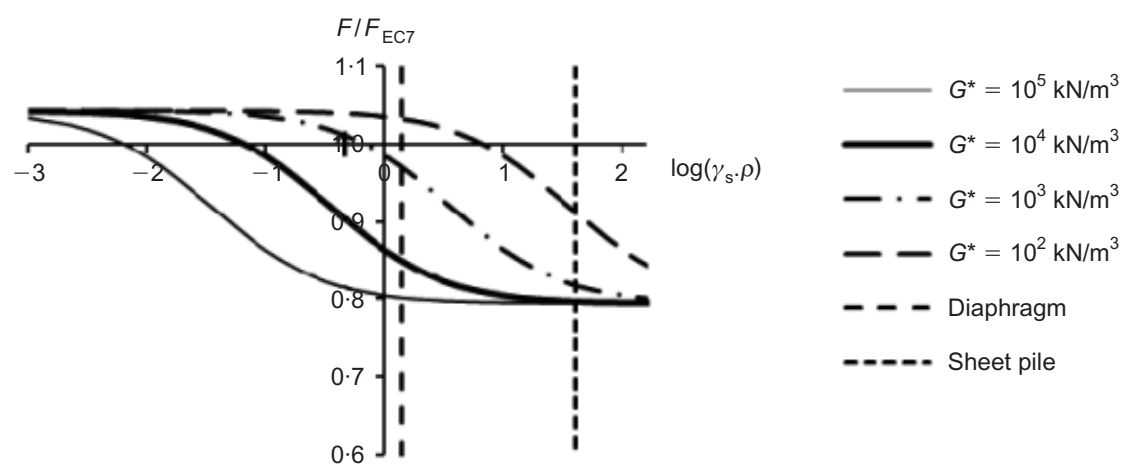

Fig. 6. Comparison between MSD and conventional limit equilibrium (EC7) prop loads for different values of soil stiffness and wall flexibility for $\varphi_{\text {ult }}^{\prime}=20^{\circ}$ and steady-state seepage into excavation from water table at original ground level (soil-wall friction angle $\delta_{\mathrm{s}}=\frac{2}{3} \varphi_{\text {ult }}^{\prime}$ )

\section{RELATIVE SOIL/WALL STIFFNESS}

It is remarkable that the curves presented in each of Figs $2,3,5$ and 6 for different values of $G^{*}$ have the same shape, and are separated along the $\log \left(\gamma_{\mathrm{s}} \rho\right)$ axis by one order of magnitude. By plotting $M / M_{\mathrm{EC} 7}$ or $F / F_{\mathrm{EC} 7}$ against $\log \left(G^{*} \rho\right)$ for either zero pore water pressures or a state of linear seepage, a single curve is obtained for a given value of $\varphi_{\text {ult }}^{\prime}$ (Figs 7 and 8).

The presence of pore water pressures results in a less pronounced rate of reduction in both the maximum bending moment and prop load with increasing relative soil-wall stiffness than when the pore water pressures are zero. This is because increasing the pore water pressure reduces the influence of wall flexibility, in that only the effective stress component of the total lateral stress acting on the wall can be redistributed by wall flexibility effects (Powrie, 1997; Bourne-Webb et al., 2007). For the same reason, decreasing the soil strength has a greater effect on the rate of reduction of maximum bending moment and prop load with increasing relative soil-wall stiffness when the pore water pressures are low (zero).

As already discussed, for stiff walls with a relatively low value of $\log \left(G^{*} \rho\right)$, the calculated increase in bending moments and prop load above the EC7 values is perhaps unfeasibly high for $\varphi_{\text {ult }}^{\prime}=30^{\circ}$. In this case, it will be important to take into account the likely difference in

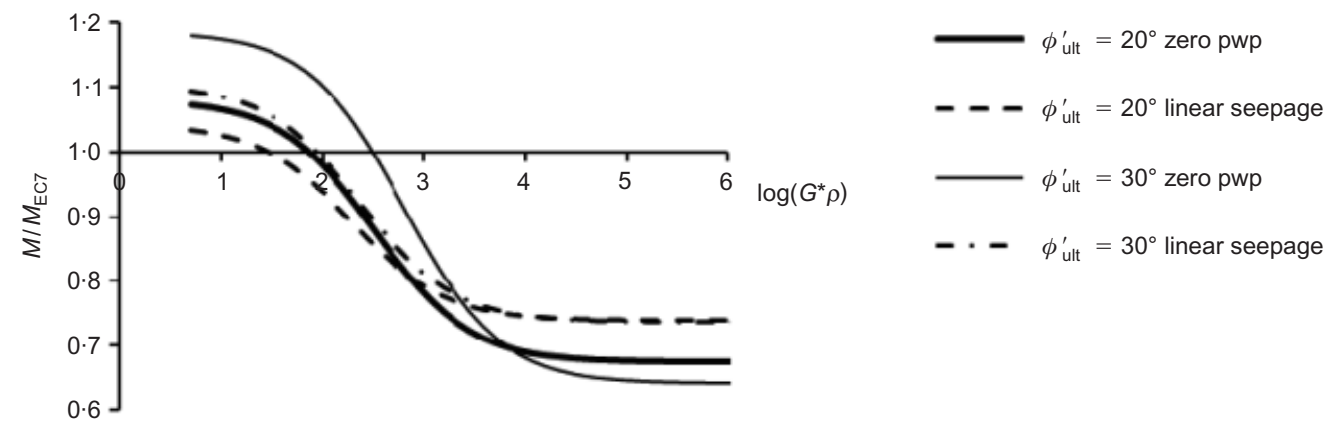

Fig. 7. Comparison between MSD and conventional limit equilibrium (EC7) maximum bending moments for different values of $\log \left(G^{*} \rho\right)$ and different conditions of pore water pressure when $\varphi_{\text {ult }}^{\prime}=20^{\circ}$ and $\varphi_{\text {ult }}^{\prime}=30^{\circ}$ (soil-wall friction angle $\delta_{\mathrm{s}}=\frac{2}{3} \varphi_{\text {ult }}^{\prime}$ ) 


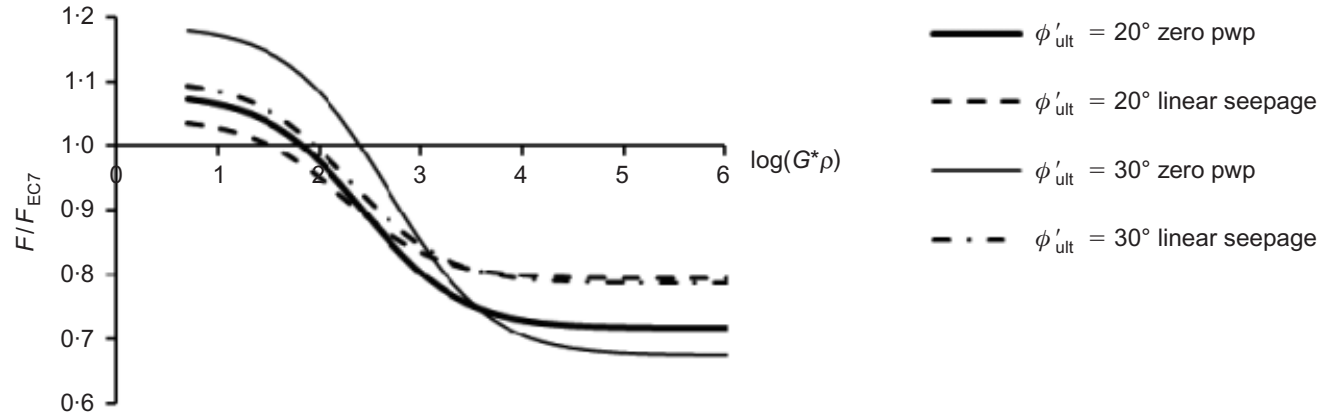

Fig. 8. Comparison between MSD and conventional limit equilibrium (EC7) prop loads for different values of $\log \left(G^{*} \rho\right)$ and different conditions of pore water pressure when $\varphi_{\text {ult }}^{\prime}=20^{\circ}$ and $\varphi_{\text {ult }}^{\prime}=30^{\circ}$ (soil-wall friction angle $\left.\delta_{\mathrm{s}}=\frac{2}{3} \varphi_{\mathrm{ult}}^{\prime}\right)$

strength mobilisation rates with shear strain behind and in front of the wall. Nonetheless, Figs 7 and 8 show that the MSD method as developed in this paper offers generic moment and prop load reduction curves for possible use in design. It also demonstrates that $G^{*} \rho=G^{*} H^{4} / E I$, where $G^{*}$ is the rate of increase in shear modulus with depth, $H$ is the overall wall height and $E I$ is its bending stiffness per metre run, is the appropriate dimensionless group for characterising relative soil/wall stiffness (Li, 1990; Powrie, 1997). Although the units are inevitably similar, the group and the concept underlying it are different from those proposed by previous authors, such as Clough et al. (1989), who used the unit weight of water rather than the rate of increase in soil stiffness with depth; Rowe (1955), whose soil stiffness parameter, $m$, was different; and Potts \& Bond (1994), who used $E_{\mathrm{s}, \mathrm{av}} H^{4} / E I$, where $E_{\mathrm{s}, \mathrm{av}}$ was the average Young's modulus over the depth of the wall, and EI was ostensibly in $\mathrm{kN} \mathrm{m}^{2}$ rather than $\mathrm{kN} \mathrm{m}^{2} / \mathrm{m}$.

\section{CRITICAL FLEXIBILITY NUMBER}

For a retaining wall propped at the crest, wall deformation occurs partly as a result of rigid body rotation about the prop and partly as a result of bending, as shown in Fig. 9. On the basis of tests on model embedded walls anchored near the crest retaining dry sand, Rowe (1952) found that the lateral stress distribution in front of the wall depended on the relative importance of the bending component of wall deformation, and hence on the bending stiffness of the wall. If the wall was stiff, so that the deflection at the excavation level was less than that at the toe, the stress distribution in front of the wall was approximately linear, and there was no reduction in the bending moments or anchor loads compared with those calculated in a limit equilibrium analysis with fully active lateral pressures and passive pressures reduced by a factor $F_{\mathrm{p}}$. If the wall was more flexible, so that the deflection at the excavation level was greater than that at the toe, the centroid of the stress distribution in front of the wall was raised, and a reduction in both the bending moments and anchor loads was observed.

A stiff wall could be defined as a wall in which bending deflections are small enough in comparison with displacements due to rigid body rotation not to affect the linearity of the lateral stress distribution. Transition from a stiff to a flexible wall is indicated by a critical value of wall flexibility $\rho=H^{4} / E I$, denoted $\rho_{\mathrm{c}}$. According to Rowe (1952), $\rho_{\mathrm{c}}$ is reached when bending effects are such that the total deflection at the excavation level becomes equal to that at the toe.

From Fig. 9, the deformations (normalised by the overall wall height $H$ ) at the toe of a retaining wall propped at the crest, $\delta_{\mathrm{t}}$, and at excavation level, $\delta_{\mathrm{e}}$, can be divided into

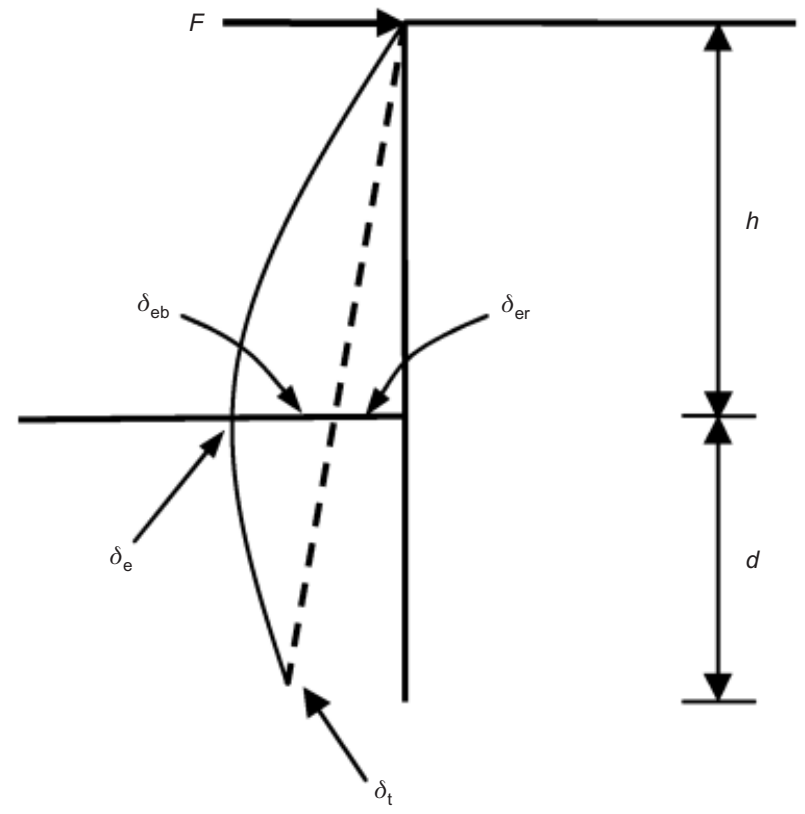

Fig. 9. Components of wall deformation due to rigid body rotation and wall bending

components $\delta_{\text {tr }}$ and $\delta_{\text {er }}$ due to rigid body rotation, and $\delta_{\mathrm{tb}}$ $(=0)$ and $\delta_{\mathrm{eb}}$ due to wall bending.

From the soil displacement fields shown in Fig. 1, the normalised components of wall deformation, $\delta_{\mathrm{t}}, \delta_{\mathrm{er}}$ and $\delta_{\mathrm{eb}}$, are related to the wall rotations at the crest by

$$
\begin{aligned}
& \delta_{\mathrm{t}}=\delta \theta_{4} \\
& \delta_{\mathrm{er}}=\delta \theta_{4} n \\
& \delta_{\mathrm{eb}}=\left(\delta \theta_{2}+\delta \theta_{3}\right) n
\end{aligned}
$$

where $n=h / H$.

$\delta_{\mathrm{t}}$ is plotted against the dimensionless quantity $\gamma_{\mathrm{s}} / G^{*}$ in Fig. 10, and $\delta_{\mathrm{eb}}$ is plotted against the dimensionless quantity $\gamma_{\mathrm{s}} \rho$ in Fig. 11, for $\varphi_{\text {ult }}^{\prime}=30^{\circ}, \delta_{\mathrm{s}}=2 \varphi_{\text {ult }}^{\prime} / 3$ and zero pore water pressures.

Figures 10 and 11 show that, following Powrie (1997) and Li (1990), the maximum deformation due to rigid body rotation is proportional to the soil stiffness parameter $\gamma_{\mathrm{s}} / G^{*}$, and the maximum deformation due to wall bending is proportional to the wall flexibility $\gamma_{\mathrm{s}} \rho$ but independent of the soil stiffness. These observations also apply for different values of $\varphi_{\text {ult }}^{\prime}$.

Figure 12 shows $\delta_{\mathrm{t}}$ and $\delta_{\mathrm{eb}}$ plotted against the relative soil/wall stiffness, $\log \left(G^{*} \rho\right)$, for $\varphi_{\text {ult }}^{\prime}=30^{\circ}, \quad \gamma_{\mathrm{s}} / G^{*}=$ $2 \times 10^{-4}$ and zero pore water pressures. The value of $G^{*} \rho$ at which $\delta_{\mathrm{t}}=\delta_{\mathrm{eb}}$ in Fig. 12 is that beyond which the 


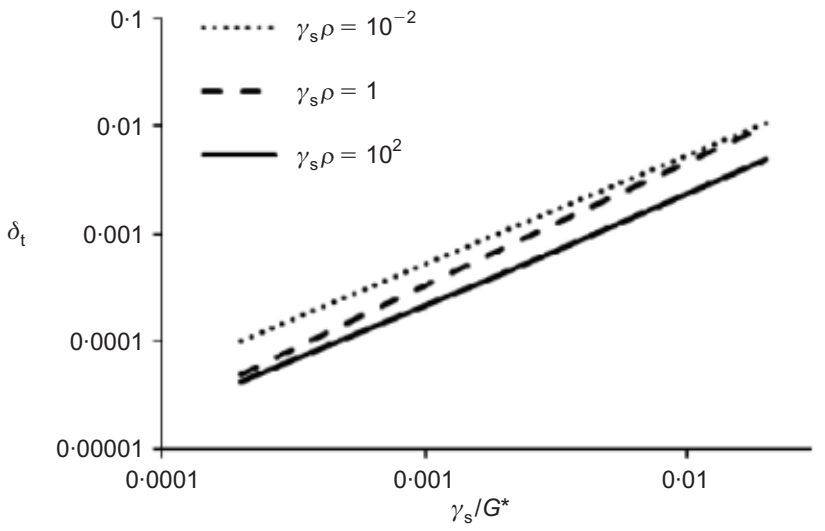

Fig. 10. Normalised deformation due to rigid body rotation at toe, $\delta_{\mathrm{t}}$, as function of $\gamma_{\mathrm{s}} / G^{*}$ (soil-wall friction angle $\delta_{\mathrm{s}}=\frac{2}{3} \varphi_{\mathrm{ult}}^{\prime}$ )

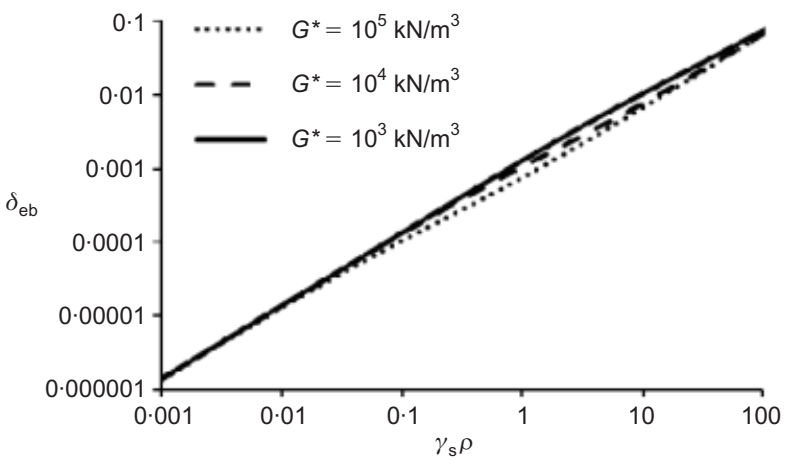

Fig. 11. Normalised component of deformation due to wall bending at excavation level, $\delta_{\mathrm{eb}}$, as function of $\gamma_{\mathrm{s}} \rho$ (soil-wall friction angle $\delta_{\mathrm{s}}=\frac{2}{3} \varphi_{\mathrm{ult}}^{\prime}$ )

maximum bending moments calculated according to the MSD approach begin to reduce below those calculated in a conventional limit equilibrium calculation according to EC7 in Fig. 7. This value of $G^{*} \rho$ will be termed the critical flexibility number, and will be denoted $R_{\mathrm{c}} . R_{\mathrm{c}}$ is reached when the deformation due to rigid body rotation at the toe, $\delta_{t}$, is equal to the component of deformation due to wall bending at excavation level, $\delta_{\mathrm{eb}}$, rather than to the total

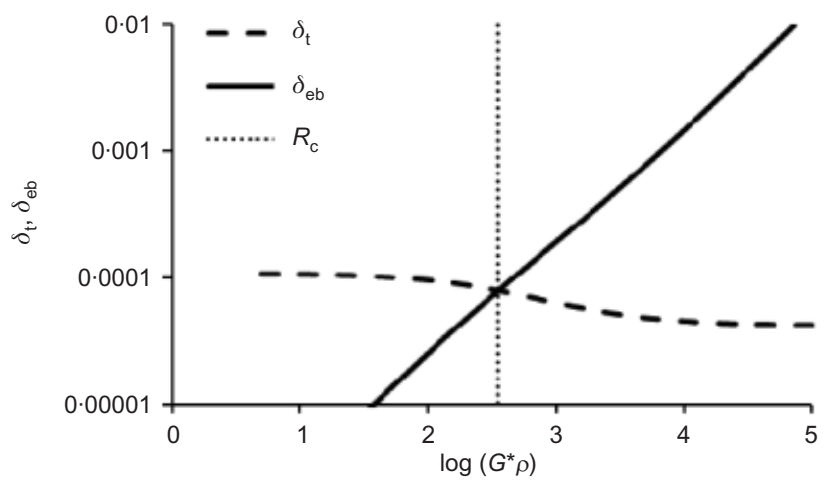

Fig. 12. Determination of critical flexibility number for $\varphi_{\text {ult }}^{\prime}=30^{\circ}, \gamma_{\mathrm{s}} / G^{*}=2 \times 10^{-4}$ and zero pore water pressure (soilwall friction angle $\delta_{\mathrm{s}}=\frac{2}{3} \varphi_{\mathrm{ult}}^{\prime}$ ) deformation at excavation level, $\delta_{\mathrm{e}}-$ the criterion adopted by Rowe (1955).

Further calculations demonstrate that $R_{\mathrm{c}}$ is independent of $\gamma_{\mathrm{s}} / G^{*}$, but Fig. 13 shows that $R_{\mathrm{c}}$ is proportional to $\varphi_{\mathrm{ult}}^{\prime}$, and for a given value of $\varphi_{\text {ult }}^{\prime}$ increases as the pore water pressures are reduced. The effect of pore water pressure becomes more pronounced as $\varphi_{\text {ult }}^{\prime}$ increases.

\section{COMPARISON OF MSD APPROACH WITH PREVIOUS STUDIES}

Comparison with Rowe's analysis of anchored sheet-pile walls (Rowe, 1955), which led to his moment reduction curves, is complicated, and is not attempted here because of

(a) differences in the comparator limit equilibrium calculations (fully active pressures behind the wall and factored passive pressures in front, compared with the same factor of safety on soil strength on both sides of the wall as specified in EC7), and

(b) the starting or pre-excavation stress state of the soil (the MSD approach as presented in this paper has assumed a starting condition of zero mobilised strength at zero strain, i.e. a lateral earth pressure coefficient of unity; in Rowe's tests and analyses, the initial condition would have been closer to a lateral earth pressure coefficient of perhaps $0 \cdot 5$ ).

Potts \& Fourie (1985) presented the results of finite-element analyses on the effect of wall flexibility on wall movements, bending moments and prop loads. Pore water pressures were set to zero, and the pre-excavation earth pressure coefficient, $K_{0}$, was assigned a value of $0.5,1,1.5$ or 2 .

Tables 2 and 3 detail the soil and wall parameters adopted in the Potts \& Fourie (1985) analyses. For $\delta_{\mathrm{s}}=\varphi_{\mathrm{ult}}^{\prime}$, a factor of safety $F_{\mathrm{r}}=2$ corresponds to a factor of safety applied equally to the soil strength behind and in front of the wall, $F_{\mathrm{s}}=1.26$, which is similar to the value recommended by EC7. The rate of increase of the soil Young's modulus with depth, $E_{\mathrm{s}}^{*}$, Poisson's ratio, $v$, and $G^{*}$ were assumed not to vary with soil strain. For consistency with the MSD approach, the units of $\rho$ shown in Table 3 are $\mathrm{m}^{3} / \mathrm{kN}$, and correspond to wall bending stiffness $(E I)$ in $\mathrm{kN} \mathrm{m}^{2} / \mathrm{m}$.

The MSD results may be compared with the finite-element results for a pre-excavation lateral earth pressure coefficient

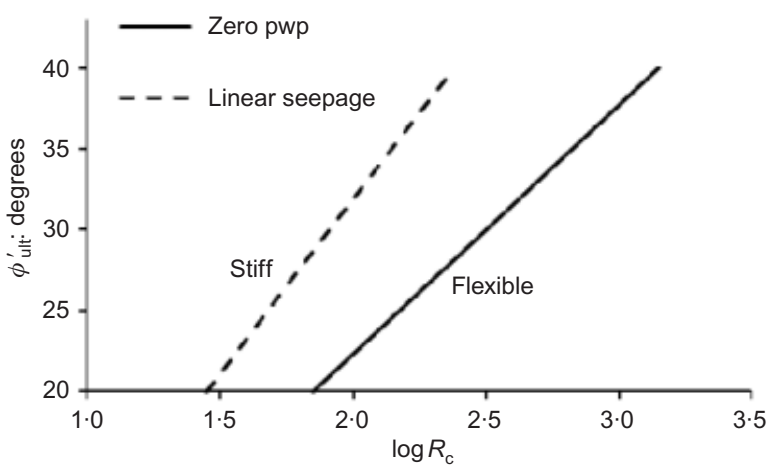

Fig. 13. Critical flexibility number $R_{\mathrm{c}}$ against $\varphi_{\mathrm{ult}}^{\prime}$ for different pore water pressure conditions (soil-wall friction angle $\left.\delta_{\mathrm{s}}=\frac{2}{3} \varphi_{\mathrm{ult}}^{\prime}\right)$

Table 2. Soil strengths and geometrical parameters investigated by Potts \& Fourie (1985)

\begin{tabular}{l|c|c|c|c|c|c}
\hline$\varphi^{\prime}:$ degrees & $\delta_{\mathrm{s}}:$ degrees & $\gamma_{\mathrm{s}}: \mathrm{kN} / \mathrm{m}^{3}$ & $n=h / H$ & $H: \mathrm{m}$ & $F_{\mathrm{r}}$ for $\delta_{\mathrm{s}}=\varphi_{\text {ult }}^{\prime}$ & $F_{\mathrm{s}}$ for $\delta_{\mathrm{s}}=\varphi_{\text {ult }}^{\prime}$ \\
\hline 25 & 25 & 20 & 0.663 & 20 & 2 & $1 \cdot 26$ \\
\hline
\end{tabular}


Table 3. Soil and wall stiffness parameters investigated by Potts \& Fourie (1985)

\begin{tabular}{l|c|c|c|c|c|c}
\hline Value range & $\gamma_{\mathrm{s}}: \mathrm{kN} / \mathrm{m}^{3}$ & $\rho: \mathrm{m}^{3} / \mathrm{kN}$ & $E_{\mathrm{s}}^{*}: \mathrm{kN} / \mathrm{m}^{3}$ & $v$ & $G^{*}: \mathrm{kN} / \mathrm{m}^{3}$ & $\log \left(G^{*} \rho\right)$ \\
\hline Minimum & 20 & $3 \cdot 16 \times 10^{-2}$ & $6 \times 10^{3}$ & $0 \cdot 2$ & $2.5 \times 10^{3}$ & $1 \cdot 9$ \\
Maximum & 20 & 31.62 & $6 \times 10^{3}$ & $0 \cdot 2$ & $2.5 \times 10^{3}$ & $4 \cdot 9$ \\
\hline
\end{tabular}

$K_{0}=1$, as this corresponds to the assumption in the MSD analyses presented in this paper of zero mobilised soil strength $\left(\varphi_{\mathrm{mob}}^{\prime}=0\right)$ at zero strain.

Figures 14 and 15 compare the ratios of maximum bending moments and prop loads with the values derived from a conventional limit equilibrium calculation, plotted against $\log \left(G^{*} \rho\right)$, calculated using the MSD approach for the parameter values given in Tables 2 and 3 with those from the Potts \& Fourie (1985) finite-element analysis for $F_{\mathrm{r}}=2$ (corresponding to $F_{\mathrm{s}}=1 \cdot 26$ ) and $K_{0}=1$.

The MSD method gives a smaller reduction and a smaller rate of reduction in bending moments with increasing relative soil-wall stiffness than the finite-element results (Fig. 14). The calculated prop load reductions (Fig. 15) seem consistent between the two methods at high values of $G^{*} \rho$, but diverge as $G^{*} \rho$ decreases. For stiff walls, Potts \& Fourie (1985) report prop loads exceeding the limit equilibrium values. For $\varphi_{\text {ult }}^{\prime}=25^{\circ}$, full soil $/$ wall friction $\left(\delta_{\mathrm{s}}=\varphi_{\text {ult }}^{\prime}\right)$ and conditions of zero pore water pressure, the MSD method and finite-element analysis give critical flexibility numbers, $R_{\mathrm{c}}$, of 2.1 and 1.9 respectively (Fig. 14), a difference of about $10 \%$.

The differences between the methods apparent in Fig. 14 may arise from a combination of the following factors.

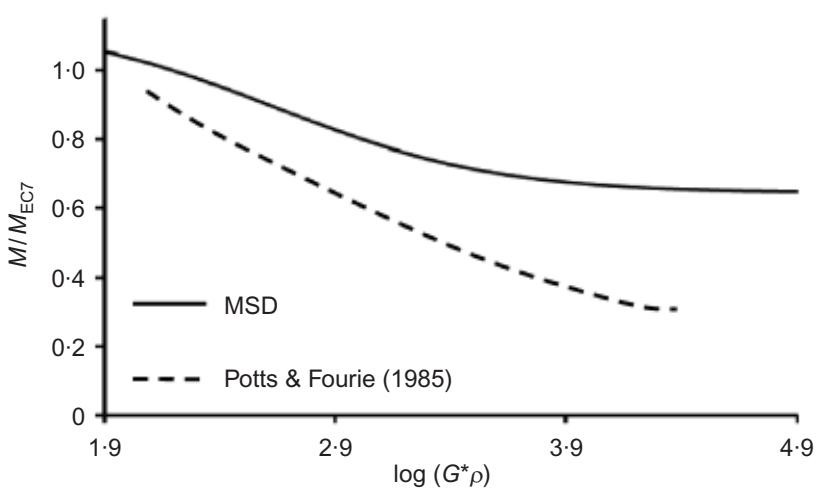

Fig. 14. Comparison between MSD and Potts \& Fourie (1985) bending moment reduction curves: $M / M_{\mathrm{EC} 7}$ against $\log \left(G^{*} \rho\right)$

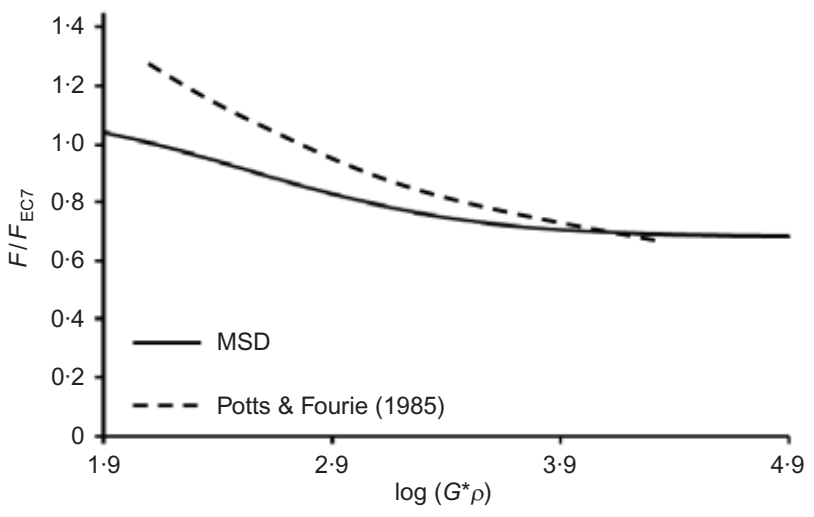

Fig. 15. Comparison between MSD and Potts \& Fourie (1985) prop load reduction curves: $F / F_{\mathrm{EC} 7}$ against $\log \left(G^{*} \rho\right)$ (a) In the Potts \& Fourie (1985) analyses, the soil stiffness does not vary with strain whereas in the MSD approach it does, according to the hyperbolic equation. The decrease in soil stiffness with increasing strain will tend to reduce the extent to which high local bending affects the linearity of the stress distribution (Powrie, 1997), and hence the reduction in bending moments.

(b) The effect of shear stresses on the back of the $1 \mathrm{~m}$ thick wall in the finite-element analysis will reduce bending moments compared with those calculated for an idealised wall of zero thickness (Powrie \& Li, 1991; Day \& Potts, 1993).

(c) It is generally accepted that limit equilibrium methods tend to underestimate prop loads compared with full soil-structure interaction analyses (Gaba et al., 2003), although Rowe's results (Rowe, 1952, 1955) did not show that trend.

(d) The idealised strain fields used in the MSD approach are approximate in nature.

\section{SUMMARY AND CONCLUSIONS}

Kinematically admissible soil strain fields have been introduced to enable the mobilisable strength design (MSD) method to be applied to flexible retaining walls propped at the crest. A calculation procedure has been developed for determining the deflected shape, bending moments and prop loads for such a wall. The MSD approach gives fundamental insights into the relative soil-wall stiffness problem, and enables the factors affecting it to be investigated from a physical point of view. It also offers a straightforward and rational way of relating the mobilised soil strength to wall and soil behaviour, taking into account both the wall flexibility and the variation in soil stiffness with depth and strain.

It is shown that rigid body rotation of the wall is proportional to the dimensionless parameter $\gamma_{\mathrm{s}} / G^{*}$, and bending deformation to $\gamma_{\mathrm{s}} H^{4} / E I$, and hence that their relative importance (and the effects of soil-wall flexibility) are appropriately characterised by the dimensionless relative soil-wall stiffness parameter $R=G^{*} H^{4} / E I$.

The maximum bending moments and prop loads obtained from the MSD calculation have been compared with those calculated on the basis of a uniform mobilised strength, following the factored ULS limit equilibrium calculation given in EC7. A range of pore water pressure conditions, soil strengths and soil and wall stiffnesses have been considered. Remarkably, a single curve is obtained for a given value of soil strength and given pore water pressure conditions, when either the normalised maximum bending moment or the normalised prop load is plotted against the logarithm of $G^{*} H^{4} / E I$.

As in previous studies, the maximum bending moment and prop load reduce below the limit equilibrium values as the relative wall flexibility increases. The reduction in bending moment and prop load is less pronounced and less dependent on the soil strength at higher pore water pressures.

A critical relative soil-wall stiffness has been identified at which the bending moments start to fall below those calcu- 
lated in a limit equilibrium calculation as a result of wall bending effects, as occurring when the bending deflection at excavation level is equal to the deflection due to rigid body rotation at the toe. This may be used to distinguish a 'stiff' from a 'flexible' system: its numerical value has been shown to depend on the soil strength and the pore water pressure regime. The critical flexibility number derived from the MSD approach is broadly in agreement with that inferred from previous finite-element analyses.

The generic bending moment and prop load reduction curves developed will facilitate the rapid estimation of wall flexibility effects on these structural stress resultants in a way that is not currently possible.

\section{ACKNOWLEDGEMENTS}

The research described in this paper was sponsored by and carried out in the School of Civil Engineering and the Environment, University of Southampton.

\section{APPENDIX 1}

Duncan \& Chang (1970) proposed a simple relationship for representing the soil behaviour, based on the hyperbolic equation introduced by Kondner (1963) and Kondner \& Zelasko (1963)

$$
\sigma_{1}-\sigma_{3}=\frac{\varepsilon_{\mathrm{a}}}{a+b \varepsilon}
$$

where $\sigma_{1}$ and $\sigma_{3}$ are the major and minor principal stresses respectively, $\varepsilon_{\mathrm{a}}$ is the axial strain, and $a$ and $b$ are constants, which can be derived from experimental data. According to Duncan \& Chang (1970), constants $a$ and $b$ can be related to the initial tangent Young's modulus, $E_{\mathrm{s} 0}$, and the asymptotic value of stress difference, $\left(\sigma_{1}-\sigma_{3}\right)_{\mathrm{ult}}$, which the stress-strain curve approaches at large (infinite) strain respectively

$$
\begin{aligned}
& a=\frac{1}{E_{\mathrm{s} 0}} \\
& b=\frac{1}{\left(\sigma_{1}-\sigma_{3}\right)_{\mathrm{ult}}}
\end{aligned}
$$

From the geometry of the Mohr circle of stress shown in Fig. 16, $\varphi_{\text {mob }}^{\prime}$ is given by

$$
\varphi_{\mathrm{mob}}^{\prime}=\sin ^{-1}\left(\frac{t}{s^{\prime}}\right)
$$

where $t$ is the radius of the Mohr circle

$$
t=\frac{1}{2}\left(\sigma_{1}^{\prime}-\sigma_{3}^{\prime}\right)
$$

and $s^{\prime}$ is the average effective stress

$$
s^{\prime}=\frac{1}{2}\left(\sigma_{1}^{\prime}+\sigma_{3}^{\prime}\right)
$$
by

In a compression triaxial test, the maximum shear strain is given

$$
\gamma=\frac{1}{2}\left(3 \varepsilon_{\mathrm{a}}-\varepsilon_{\mathrm{vol}}\right)
$$

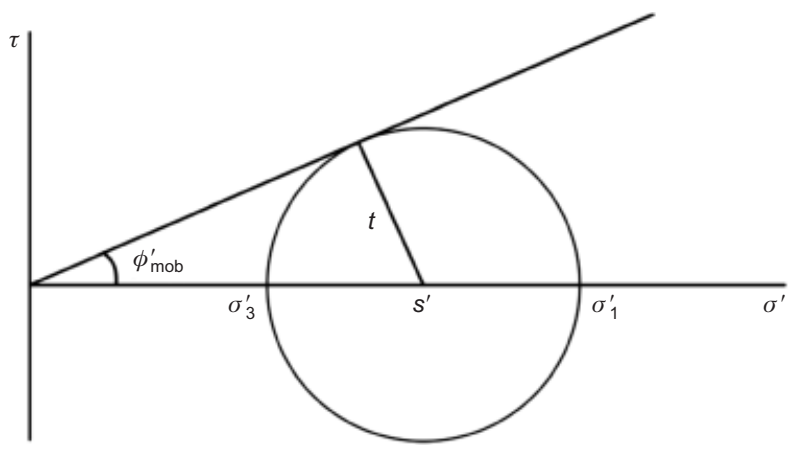

Fig. 16. Mohr circle of stress for triaxial test where $\varepsilon_{\mathrm{vol}}$ and $\varepsilon_{\mathrm{a}}$ are the volumetric and axial strains. Assuming zero volume change

$$
\varepsilon_{\mathrm{vol}}=0
$$

Thus

$$
\gamma=1 \cdot 5 \varepsilon_{\mathrm{a}}
$$

From equations (34) and (38), the hyperbolic equation (30) can be rewritten in the form

$$
t=\frac{\gamma}{3 a+2 b \gamma}
$$

In equation (39) the parameters $a$ and $b$ are related to the initial shear modulus $G_{0}$, Poisson's ratio $v$ and shear stresses at failure, $t_{\mathrm{f}}$, by

$$
\begin{aligned}
& a=\frac{1}{2 G_{0}(1+v)} \\
& b=\frac{1}{2 t_{\mathrm{f}}}
\end{aligned}
$$

\section{APPENDIX 2}

For the soil behind the wall (active side), from equations (33), (34), (35) and (39)

$$
\varphi_{\text {mob }}^{\prime}=\sin ^{-1}\left[\frac{\gamma}{3 a \sigma_{1}^{\prime}+\gamma\left(2 \sigma_{1}^{\prime} b-1\right)}\right]
$$

For the soil in front of the wall (passive side), from equations (33) (34), (35) and (39)

$$
\varphi_{\text {mob }}^{\prime}=\sin ^{-1}\left[\frac{\gamma}{3 a \sigma_{3}^{\prime}+\gamma\left(1+2 \sigma_{3}^{\prime} b\right)}\right]
$$

Equations (42) and (43) can be written more simply in the form of equation (19), where for the active side

$$
\begin{aligned}
& A=3 a \sigma_{1}^{\prime} \\
& B=2 \sigma_{1}^{\prime} b-1
\end{aligned}
$$

and for the passive side

$$
\begin{aligned}
& A=3 a \sigma_{3}^{\prime} \\
& B=1+2 \sigma_{3}^{\prime} b
\end{aligned}
$$

Parameters $a, b$ are given by equations (40) and (41).

From Fig. 16

$$
\begin{aligned}
& \sigma_{1}^{\prime}-\sigma_{3}^{\prime}=\frac{2 \sigma_{1}^{\prime} \sin \varphi_{\text {ult }}^{\prime}}{1+\sin \varphi_{\text {ult }}^{\prime}} \\
& \sigma_{1}^{\prime}-\sigma_{3}^{\prime}=\frac{2 \sigma_{3}^{\prime} \sin \varphi_{\text {ult }}^{\prime}}{1-\sin \varphi_{\text {ult }}^{\prime}}
\end{aligned}
$$

Therefore, from equations (41), (48) and (49), $b$ can be expressed as

$$
\begin{aligned}
b & =\frac{1}{\sigma_{1}^{\prime}-\sigma_{3}^{\prime}} \\
& =\frac{1+\sin \varphi_{\mathrm{ult}}^{\prime}}{2 \sigma_{1}^{\prime} \sin \varphi_{\mathrm{ult}}^{\prime}} \\
b & =\frac{1}{\sigma_{1}^{\prime}-\sigma_{3}^{\prime}} \\
& =\frac{1-\sin \varphi_{\mathrm{ult}}^{\prime}}{2 \sigma_{3}^{\prime} \sin \varphi_{\mathrm{ult}}^{\prime}}
\end{aligned}
$$

For conditions of zero pore water pressure, parameters $A$ and $B$ can be calculated as follows. For the soil behind the wall (active side) substitution of $a$ given by equation (40) and $v^{\prime}=0 \cdot 5, G^{*}=$ $G / z, \sigma_{1}^{\prime}=\sigma_{\mathrm{v}}^{\prime}=\gamma_{\mathrm{s}} z$, where $z$ is the depth from the original ground level, into equation (44) gives

$$
A=\frac{\gamma_{\mathrm{s}}}{G^{*}}
$$

Substitution of $b$ given by equation (50) into equation (45) gives:

$$
B=\frac{1}{\sin \varphi_{\mathrm{ult}}^{\prime}}
$$


For the soil in front of the wall (passive side), substitution of $a$ given by equation (40) and $v^{\prime}=0 \cdot 5, G^{*}=G /(z-h), \sigma_{3}^{\prime}=\sigma_{\mathrm{v}}^{\prime}=\gamma_{\mathrm{s}}(z-h)$ into equation (46) gives equation (52). Substitution of $b$ given by equation (51) into equation (47) gives equation (53). From the above, parameters $A$ and $B$ can be expressed by equations (52) and (53) for both the active and passive sides.

For pore water pressure conditions corresponding approximately to a state of linear seepage around the wall into the excavation from an original water table at ground level, parameter $B$ is derived from equation (53) as already explained, and parameter $A$ is calculated as follows.

For the soil behind the wall (active side)

$$
\sigma_{1}^{\prime}=\sigma_{\mathrm{v}}^{\prime}=z\left[\gamma_{\mathrm{s}}-\left(\frac{\mathrm{d} u}{\mathrm{~d} z}\right)_{\mathrm{a}}\right]
$$

From equations (40), (44) and (54)

$$
A=3 z\left[\frac{\gamma_{\mathrm{s}}-(\mathrm{d} u / \mathrm{d} z)_{\mathrm{a}}}{2 G_{0}(1+v)}\right]
$$

For $v^{\prime}=0.5$ and $G^{*}=G / z$, equation (55) gives

$$
A=\frac{\gamma_{\mathrm{s}}-(\mathrm{d} u / \mathrm{d} z)_{\mathrm{a}}}{G^{*}}
$$

For the soil in front of the wall (passive side)

$$
\sigma_{3}^{\prime}=\sigma_{\mathrm{v}}^{\prime}=(z-h)\left[\gamma_{\mathrm{s}}-(\mathrm{d} u / \mathrm{d} z)_{\mathrm{p}}\right]
$$

From equations (40), (46) and (57)

$$
A=3(z-h)\left[\frac{\gamma_{\mathrm{s}}-(\mathrm{d} u / \mathrm{d} z)_{\mathrm{p}}}{2 G_{0}(1+v)}\right]
$$

For $v^{\prime}=0.5$ and $G^{*}=G /(z-h)$, equation (58) gives

$$
A=\frac{\gamma_{\mathrm{s}}-(\mathrm{d} u / \mathrm{d} z)_{\mathrm{p}}}{G^{*}}
$$

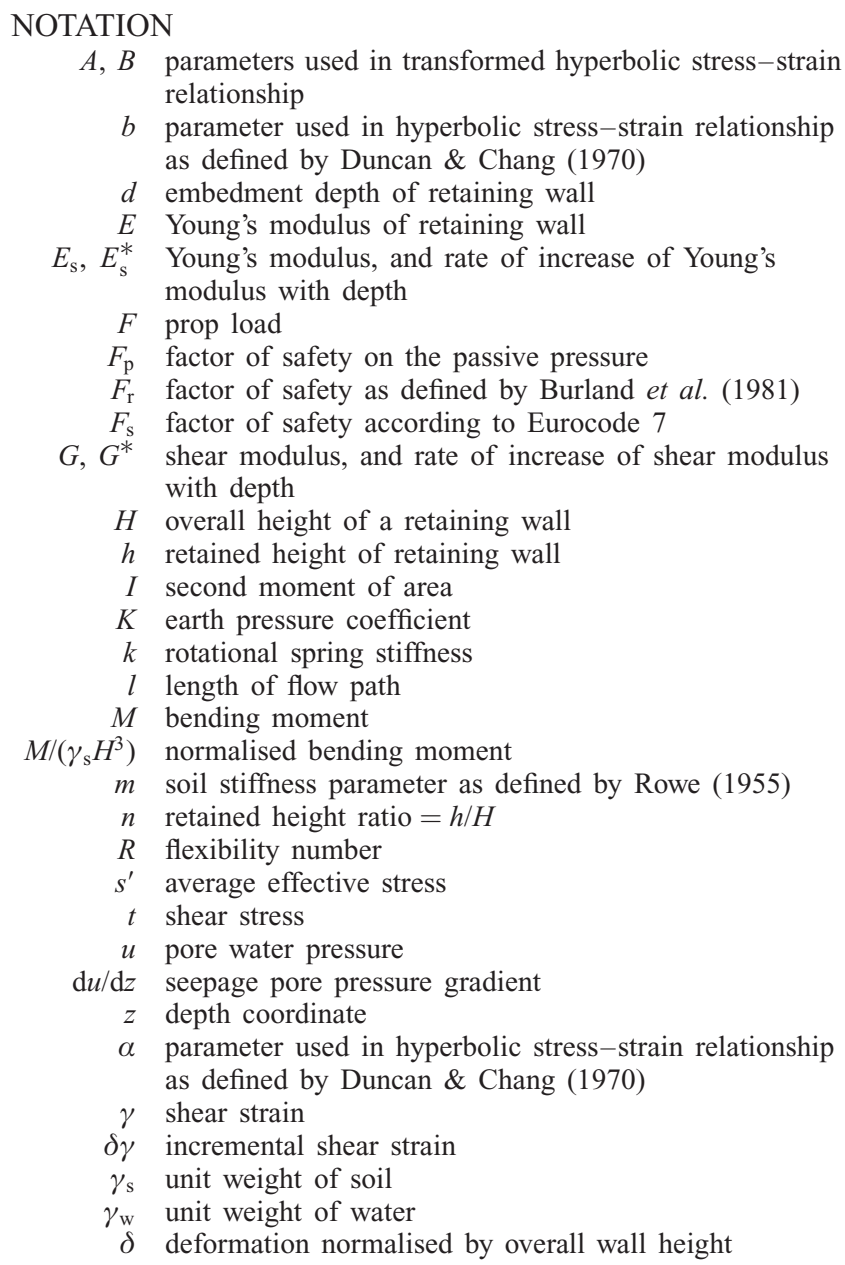

$\delta_{\mathrm{S}}$ angle of soil-wall friction

$\varepsilon$ strain

$\theta$ relative rotation between wall sections

$\delta \theta$ relative rotation

$v, v^{\prime} \quad$ undrained and drained Poisson's ratio

$\rho$ wall flexibility as defined by Rowe $(1952,1955)$

$\sigma$ total stress

$\sigma^{\prime}$ effective stress

$\tau$ shear stress

$\phi^{\prime} \quad$ soil strength

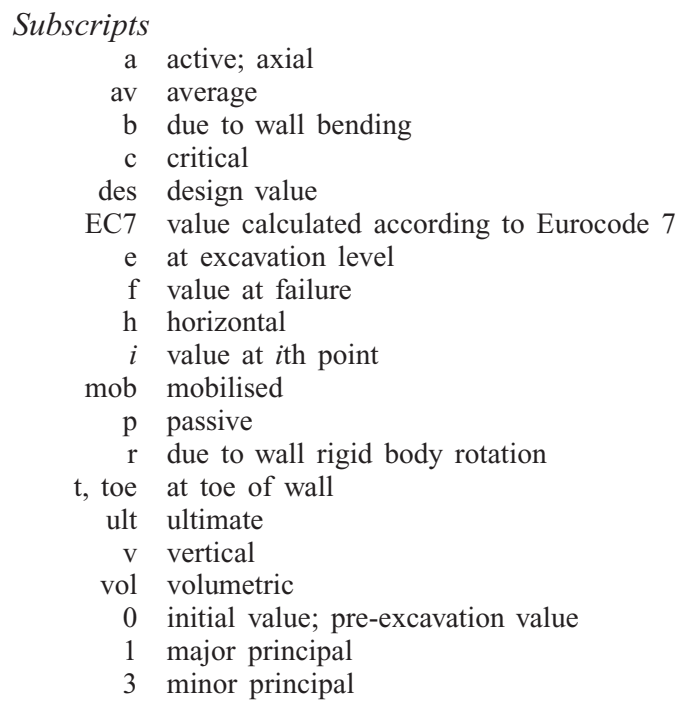

\section{REFERENCES}

Allman, M. A. \& Atkinson, J. H. (1992). Mechanical properties of reconstituted Bothkennar soil. Géotechnique 42, No. 2, 289301, http://dx.doi.org/10.1680/geot.1992.42.2.289.

Bolton, M. D. \& Powrie, W. (1988). Behaviour of diaphragm walls in clay prior to collapse. Géotechnique 38, No. 2, 167-189, http://dx.doi.org/10.1680/geot.1988.38.2.167.

Bolton, M. D., Powrie, W. \& Symons, I. F. (1989). The design of stiff in-situ walls retaining overconsolidated clay. Part 1: Short term behaviour. Ground Engng 22, No. 8, 44-47 and 22, No. 9, $34-40$.

Bolton, M. D., Powrie, W. \& Symons, I. F. (1990). The design of stiff in-situ walls retaining overconsolidated clay. Part 2: Long term behaviour. Ground Engng 23, No. 2, 22-28.

Bourne-Webb, P. J., Potts, D. M. \& Rowbottom, D. (2007). Plastic bending of steel sheet piles. Proc. Inst. Civ. Engrs Geotech. Engng 160, No. 3, 129-140.

Bransby, P. L. \& Milligan, G. W. E. (1975). Soil deformations near cantilever sheet-pile walls. Géotechnique 25, No. 2, 75-195, http://dx.doi.org/10.1680/geot.1975.25.2.75.

British Standards Institution (2004). Eurocode 7: Geotechnical design, BS EN 1997-1:2004: Part 1. Milton Keynes, UK: BSI.

Burland, J. B., Potts, D. M. \& Walsh, N. M. (1981). The overall stability of free and propped embedded cantilever retaining walls. Ground Engng 14, No. 5, 28-37.

Clough, G. W., Smith, E. M. \& Sweeney, B. P. (1989). Movement control of excavation support systems by iterative design. In Foundation engineering: Current principles and practices (ed. F. Kulhawy), Vol. 2, pp. 869-884. New York, NY, USA: American Society of Civil Engineers.

Day, R. A. \& Potts, D. M. (1993). Modelling sheet pile retaining walls. Comput. Geotech. 15, No. 3, 125-143.

Diakoumi, M. (2007). Relative soil/wall stiffness effects on retaining walls propped at the crest. $\mathrm{PhD}$ thesis, University of Southampton, UK.

Diakoumi, M. \& Powrie, W. (2009). Relative soil/wall stiffness effects on retaining walls propped at the crest. Proc. 2nd Int. Conf. on New Developments in Soil Mechanics and Geotechnical Engineering, Nicosia, 488-495. 
Duncan, M. J. \& Chang, C. Y. (1970). Nonlinear analysis of stress and strain in soils. J. Soil Mech. Found. Div. ASCE 96, No. 5, 1629-1653.

Gaba, A. R., Simpson, B., Powrie, W. \& Beadman, D. R. (2003). Embedded retaining walls: Guidance for economic design, CIRIA Report C580. London, UK: Construction Industry Research and Information Association.

Jardine, R. J., Potts, D. M., Fourie, A. B. \& Burland, J. B. (1986) Studies of the influence of non-linear stress-strain characteristics in soil-structure interaction. Géotechnique 36, No. 3, 377-396, http://dx.doi.org/10.1680/geot.1986.36.3.377.

Kondner, R. L. (1963). Hyperbolic stress-strain response: cohesive soils. J. Soil Mech. Found. Div. ASCE 89, No. 1, 115-143.

Kondner, R. L. \& Zelasko, J. S. (1963). A hyperbolic stress-strain formulation for sands. Proc. 2nd Pan-American Conf. on Soil Mechanics and Foundation Engineering, Sao Paolo 1, 289-324.

Li, E. S. F. (1990). On the analysis of singly-propped diaphragm walls. $\mathrm{PhD}$ dissertation, University of London (King's College), UK.

Osman, A. S. \& Bolton, M. D. (2004). A new design method for retaining walls in clay. Can. Geotech. J. 41, No. 3, 451-466.

Potts, D. M. \& Bond, A. J. (1994). Calculation of structural forces for propped retaining walls. Proc. 13th Int. Conf. Soil Mech. Found. Engng, New Delhi, 823-826.
Potts, D. M. \& Fourie, A. B. (1985). The effect of wall stiffness on the behaviour of a propped retaining wall. Géotechnique 35, No. 3, 347-352, http://dx.doi.org/10.1680/geot.1985.35.3.347.

Powrie, W. (1997). Soil mechanics: Concepts and applications, 1st edn. London, UK: Spon Press.

Powrie, W. \& Li, E. S. F. (1991). Finite element analyses of an in situ wall propped at formation level. Géotechnique 41, No. 4, 499-514, http://dx.doi.org/10.1680/geot.1991.41.4.499.

Powrie, W., Pantelidou, H. \& Stallebrass, S. E. (1998). Soil stiffness in stress paths relevant to diaphragm walls in clay. Géotechnique 48, No. 4, 483-494, http://dx.doi.org/10.1680/geot.1998.48.4.483.

Rowe, P. W. (1952). Anchored sheet-pile walls. Proc. Inst. Civ. Engrs 1, No. 1, 27-70.

Rowe, P. W. (1955). A theoretical and experimental analysis of sheet-pile walls. Proc. Inst. Civ. Engrs 4, No. 1, 32-69.

Smith, P. R., Jardine, R. J. \& Hight, D. W. (1992). The yielding of Bothkennar clay. Géotechnique 42, No. 2, 257-274, http:// dx.doi.org/10.1680/geot.1992.42.2.257.

Symons, I. F. (1983). Assessing the stability of a propped, in situ retaining wall in overconsolidated clay. Proc. Inst. Civ. Engrs 75, No. 4, 617-633.

Wolfram Research (2007). Wolfram Mathematica Version 6.0 [computer program]. Champaign, IL, USA: Wolfram Research. 